\title{
Micro-Erythrocyte Sedimentation Rate in Neonatal Sepsis of a Tertiary Hospital: A Descriptive Cross-sectional Study
}

Sunil Raja Manandhar, ${ }^{1}$ Rydam Basnet ${ }^{1}$

'Neonatal Unit, Department of Pediatrics, Kathmandu Medical College Teaching Hospital, Sinamangal, Kathmandu, Nepal.

\section{ABSTRACT}

Introduction: Neonatal sepsis is the most important cause of morbidity and mortality among low birth weight and preterm babies in developing countries. The main objective of this study is to find the level of micro-Erythrocyte sedimentation rate in neonatal sepsis.

Methods: This is a descriptive cross-sectional study conducted at the neonatal unit over six months period (November 2019 to April 2020). All preterm, term and post-term babies with neonatal sepsis delivered at Kathmandu Medical College Teaching Hospital were enrolled. Ethical clearance was received from the Institutional Review Committee of Kathmandu Medical College (Ref: 181020191). Convenient sampling method was applied and statistical analysis was done with Statistical package for social sciences 19 version.

Results: Out of 75 babies, confirm sepsis is $13(17.3 \%)$, probable sepsis is $40(53.4 \%)$ and suspected sepsis is $22(29.2 \%)$. Micro-Erythrocyte sedimentation level is elevated $\left(\geq 15 \mathrm{~mm}\right.$ in $\left.1^{\text {st }} \mathrm{hr}\right)$ in $25(33.3 \%)$ babies with a mean micro-Erythrocyte sedimentation level $9.32 \pm 5.4(2-18) \mathrm{mm}$ in $1^{\text {st }} \mathrm{hr}$. The elevated micro- Erythrocyte sedimentation level was seen in relation to sepsis types and C-reactive protein.

Conclusions: The bedside micro-Erythrocyte sedimentation level aids in the diagnosis of neonatal sepsis.

Keywords: c-reactive protein; erythrocyte sedimentation rate; neonatal sepsis.

\section{INTRODUCTION}

Neonatal sepsis is the most important cause of mortality among low birth weight and preterm babies in developing countries. ${ }^{1}$ In Nepal, the neonatal mortality rate is still high (21 per 1000 live births). Causes of neonatal deaths are sepsis, perinatal asphyxia, prematurity, and low birth weight.,3 Maternal risk factors eg. Prolonged rupture of membranes (PROM) $\geq 18 \mathrm{hrs}$., positive high vaginal swab culture, intrapartum fever, and neonatal risk factors eg. birth weight $<1500 \mathrm{gm}$, gestational age $<34$ wks, low APGAR score contributes for sepsis. ${ }^{4}$

Sepsis is define as signs and symptoms of infections with or without accompanying bacteremia with the growth of bacteria within first month of life and consists of septicemia, meningitis, pneumonia, and urinary tract infection. ${ }^{5}$ Prompt diagnosis, good nursing care, and antibiotics aids to save babies with sepsis. ${ }^{6}$ Blood culture is the gold standard for sepsis diagnosis, but it is time-consuming and needs equipped lab.,8

So, the main objective is to find out the micro-ESR level

Correspondence: Dr. Sunil Raja Manandhar, Department of Pediatrics, Kathmandu Medical College Teaching Hospital, Sinamangal, Kathmandu, Nepal. Email: drsunilraja@gmail.com, Phone: +977-9803812218. 
in neonatal sepsis at a tertiary hospital.

\section{METHODS}

A descriptive cross-sectional study was carried out on neonates with neonatal sepsis at 10 bedded Neonatal Intensive Care Unit (NICU) of the Pediatrics Department of Kathmandu Medical College Teaching Hospital over six months period (November 2019 - April 2020). Perinatal Mortality Rate (PMR) of this tertiary hospital is 10 per 1000 births and Neonatal mortality rate (NMR) is 4.5 per 1000 live births. ${ }^{9}$

All preterm, term and post-term neonates admitted in the NICU with a diagnosis of suspected sepsis, probable sepsis and confirm sepsis were enrolled. Risk factors and laboratory criteria for the diagnosis of neonatal sepsis is mentioned in Box $1 .^{10}$

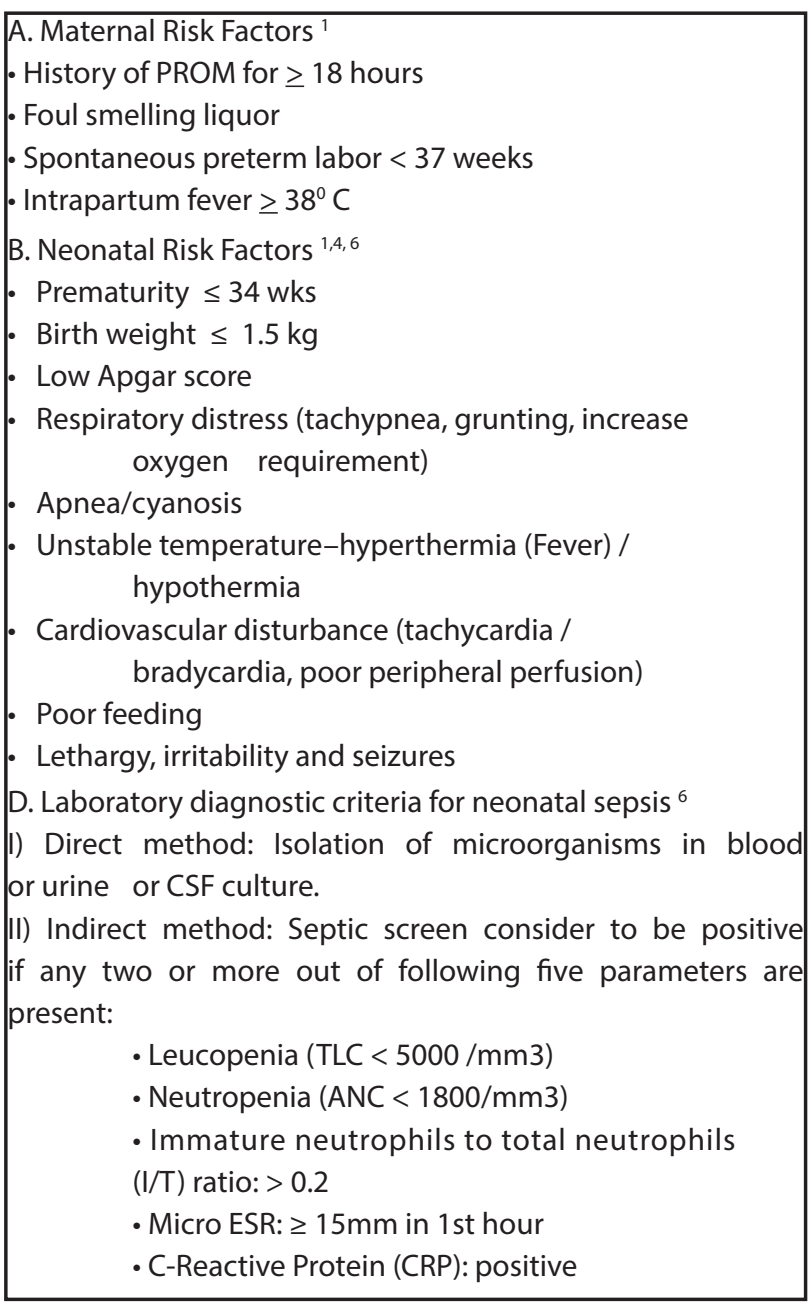

Box. 1. Risk factors, clinical features and laboratory criteria for neonatal sepsis. ${ }^{10}$

Suspected sepsis is define as neonates who fulfill the following minimum three signs and symptoms eg. sclerema, lethargy, apnea, hypotonia, poor cry, poor feeding, respiratory distress, grunting, vomiting, fever, mottling of the skin and irritability with normal five laboratory septic screening test mentioned in Box 1.,10 A neonate clinically have above mentioned clinical signs and symptoms with at least two of the five laboratory screening tests positive mentioned above in box 1 with negative blood culture is diagnosed as probable sepsis. ${ }^{11}$ Confirm sepsis is define as neonate with above mentioned clinical sign/symptoms with positive two out of the five laboratory screening tests mentioned above with having blood, urine or cerebrospinal fluid culture yielding an organism. ${ }^{11}$

Neonates fulfilling inclusion criteria were drawn venous blood for blood culture and sensitivity (CS), total leukocyte count (TLC), differential count (DC), absolute neutrophil count (ANC), hemoglobin $(\mathrm{Hb})$, microerythrocyte sedimentation rate (micro-ESR), C- reactive protein (CRP) and peripheral smear for band cells. Blood parameters TLC/ DC/ $\mathrm{Hb}$ were performed by the coulter method. In a suspected case of pneumonia, a chest $x$-ray is done and lumbar puncture (LP) is done in suspected case of meningitis. Blood CS was done via a BACTEC 9050 automation system, Becton Dickinson, Ireland. In which $3 \mathrm{ml}$ venous blood was inoculated into BACTEC Ped Plus culture vial under complete aseptic conditions. Then blood was kept in the BACTEC 9050 blood culture instrument within $2 \mathrm{hr}$ of collection and subcultures were done in positive cases to identify the causative organism according to the standard methods. Serum CRP level was measured by the semi-quantitative latex agglutination test (AVITEX CRP kits; Catalog No. OD023; supplied by Omega Diagnostics, UK). Urine routine and CS were sent in case of suspected urinary tract infection (UTI) by supra pubic aspiration. All the samples were sent to the laboratory within a half-hour of the procedure.

The following procedure was done for the estimation of micro-ESR at bedside Resuscitaire of newborns in the NICU. Blood was collected in a pre-heparinized micro hematocrit tube of $75 \mathrm{~mm}$ length with an internal diameter of $1.1 \mathrm{~mm}$ and an external diameter of $1.5 \mathrm{~mm}$ by heel prick technique. Air is not allowed to interrupt the column of blood to avoid false normal result and one end was sealed using clay wax. The micro hematocrit tube was then fixed vertically on a clay tray near the bedside with the identification of patient and the time of blood collection noted and left undisturbed for one hour. There after the distance from the highest point of the plasma column to the meniscus of the packed red cell column (height of the plasma column) of each tube was measured with a ruler after one hour. micro-ESR level was said to be elevated if the height of the plasma column measured were greater than $15 \mathrm{~mm} / \mathrm{hr}$ for all neonates irrespective of age. ${ }^{12,13}$ The clinical details and results of laboratory investigations were recorded in a pre-designed proforma. The management of neonatal sepsis was done as per the neonatal unit protocol. 
Babies with a lethal congenital malformation (eg. Meningomyelocel, Anencephaly, Gastroschisis, Diaphragmatic Hernia) and Syndromic babies were excluded. Ethical clearance was received from the Institutional Review Committee (IRC) of Kathmandu Medical College (Ref: 181020191) and written consent was taken from the parents and possible complications of neonatal sepsis were explained. The neonates were evaluated by a thorough history from mother, maternal parameters at birth, and detail clinical examinations. Gestational age assessment was done by using modified new Ballard score ${ }^{14}$ and maternal and neonatal risk factors were assessed as mentioned in Box 1. Data were analyzed in Statistical package for social sciences (SPSS 19) version in the form of frequency, tables along with mean and standard deviation. Relation of Micro ESR with respect to types of sepsis and CRP were analyzed. The sample size was calculated as follows;

Sample size $(n)=Z^{2} \times(p \times q) / e^{2}$

$$
\begin{aligned}
& \left.=(1.96)^{2} \times 0.05 \times(1-0.05) / 0.05\right)^{2} \\
& =3.84 \times 0.05 \times 0.95 / 0.0025 \\
& =0.1824 / 0.0025 \\
& =72.96 \\
& \mathrm{n}=75 \text { neonates }
\end{aligned}
$$

Where,

$$
\begin{aligned}
& n=\text { Sample size } \\
& Z=1.96 \text { at } 95 \% \text { Confidence Interval } \\
& p=\text { Prevalence of Neonatal sepsis in previous } \\
& \text { study }=5 \%\left(\text { Gomez B et al) }{ }^{15}\right.
\end{aligned}
$$

$$
\begin{aligned}
& q=1-p \\
& e=\text { Margin of error, } 5 \%
\end{aligned}
$$

A total of 75 neonates were enrolled and a convenient sampling method was applied.

\section{RESULTS}

A total of 2160 babies were delivered at KMCTH over six months period and 75 babies full filling the inclusion criteria were enrolled in this study. Among them, 45 $(60 \%)$ babies were male and most of them were term 46 (61.3\%) babies with $50 \quad(66.7 \%)$ delivered by primi mothers. The mean birth weight observed was $2611 \pm 79$ gms and the mean gestational age was $36.35 \pm 3.2$ weeks. While analyzing clinical parameters, mean respiratory rate of enrolled babies was 76.63 \pm 18.7 breaths $/ \mathrm{min}(20-110)$ and mean heart rate was $162.71 \pm 23.6$ beats $/ \mathrm{min}(82-200)$. During treatment in NICU, due to respiratory problem, 63 (84\%) babies

\begin{tabular}{|c|c|c|}
\hline \multicolumn{3}{|l|}{ Variables } \\
\hline Neonatal Characteristics & Mean & Range \\
\hline Gestational Age & $36.35 \pm 3.2$ & (24-40)wks. \\
\hline Birth weight & $2611 \pm 79$ & $(600-4200) \mathrm{gms}$ \\
\hline Apgar Score at $1 \mathrm{~min}$ (45 babies) & $7.05 \pm 1.6$ & $(1-8)$ \\
\hline Apgar Score at $5 \min$ ( 45 babies) & $8.23 \pm 1.3$ & $(3-9)$ \\
\hline Age of baby during NICU admission & $3.99 \pm 4.8$ & ( $1^{\text {st }}$ day $-22^{\text {nd }}$ days $)$ \\
\hline Clinical parameter of newborns & Mean & Range \\
\hline Respiratory rate & $76.63 \pm 18.7$ & (20-110) breaths/min \\
\hline Heart rate & $162.71 \pm 23.6$ & (82-200) beats/min \\
\hline Bubble CPAP duration (63 babies) & $58.25 \pm 33.4$ & $(12-160) \mathrm{hrs}$ \\
\hline Mechanical ventilation duration(20 babies) & $35.55 \pm 18.7$ & (4-72) hrs \\
\hline Antibiotics use duration ( 75 babies) & $8.1 \pm 4$ & (3-21)days \\
\hline Hospital Stay (70 babies) & $8.5 \pm 4.8$ & (3-28)days \\
\hline Maternal Characteristics & Mean & Range \\
\hline Maternal Age & $26.52 \pm 3.6$ & (19-39)yrs. \\
\hline Prolonged rupture of membrane (PROM) (33 mothers) & $43.97 \pm 56.5$ & (18-288)hrs \\
\hline
\end{tabular}
required Bubble CPAP ventilation with mean duration $58.25 \pm 33.4$ hrs. (12-160) and 20 (26.6\%) babies required mechanical ventilation with mean duration $35.55 \pm 18.7$ hrs. (4-72). The mean maternal age was $26.52 \pm 3.6$ yrs. (19-39) and 33 (44\%) mothers had history of PROM with a mean duration $43.97 \pm 56.5$ hrs. (18 -288). Similarly, the mean age of babies admitted in NICU was $3.99 \pm 4.8$ days and mean hospital stay for 70 babies were $8.5 \pm 4.8$ days and five babies were expired during treatment of sepsis. (Table1). 
Analyzing the maternal and neonatal risk factors for sepsis, in 33 (44\%) babies, PROM was the commonest maternal risk factor whereas prematurity 22 (29.3\%) followed by fast breathing 19 (25.3\%) were the commonest neonatal risk factors (Table 2).

\begin{tabular}{|ll|}
\hline Table 2. Risk factors for sepsis $(\mathrm{n}=75)$ & \\
\hline Maternal & $\mathrm{n}(\%)$ \\
PROM & $33(44.0)$ \\
No risk & $23(30.6)$ \\
Maternal fever & $5(6.7)$ \\
Antepartum hemorrhage (APH) & $3(4.0)$ \\
Preeclampsia & $3(4.0)$ \\
Maternal Gestational diabetes & $2(2.7)$ \\
Maternal hypothyroidism & $2(2.7)$ \\
Eclampsia & $1(1.3)$ \\
Foul-smelling liquor & $2(2.7)$ \\
Rh Iso- immunization & $1(1.3)$ \\
Total & $75(100)$ \\
Neonatal risk factors & $\mathrm{n}(\%)$ \\
Preterm & $22(29.3)$ \\
Fast breathing & $19(25.3)$ \\
Perinatal Asphyxia & $7(9.3)$ \\
Fever & $7(9.3)$ \\
Lethargy & $7(9.3)$ \\
LBW (Low Birth Weight) & $5(6.7)$ \\
Meconium aspiration & $5(6.7)$ \\
ELBW (Extremely LBW) & $2(2.7)$ \\
Big Baby & $1(1.4)$ \\
Total & $75(100)$ \\
\hline
\end{tabular}

In this study, out of 75 babies, confirmed sepsis is 13 (17.3\%), probable sepsis is 40 (53.4\%) and suspected sepsis is $22(29.3 \%)$ (Figure.1). The micro-ESR level is normal ( $\leq 15 \mathrm{~mm}$ in $1^{\text {st }} \mathrm{hr}$ ) in $50(66.7 \%)$ babies and elevated (>15mm in $1^{\text {st }} \mathrm{hr}$ ) in 25 (33.3\%) babies. The mean micro-ESR level observed in this study is 9.32 $\pm 5.4(2-18) \mathrm{mm}$ in $1^{\text {st }} \mathrm{hr}$. (Figure 2).

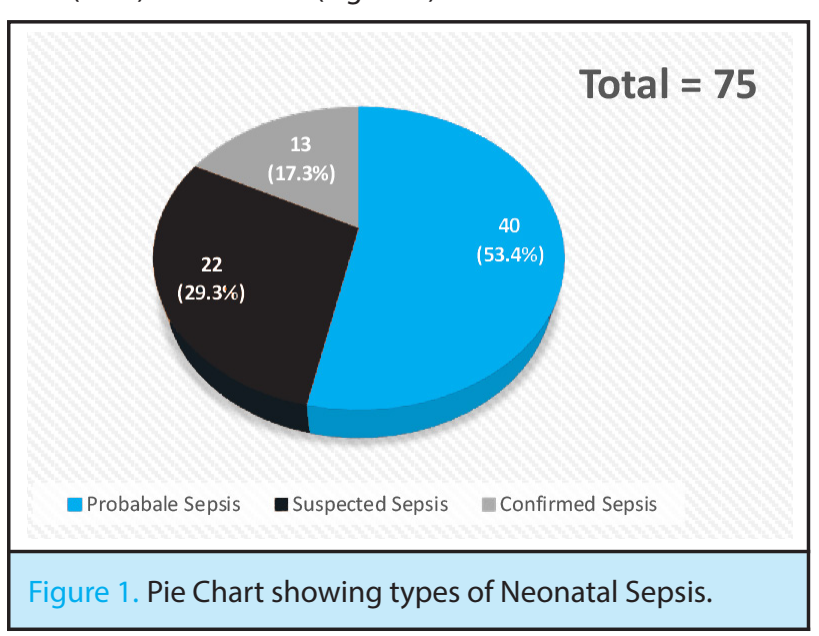

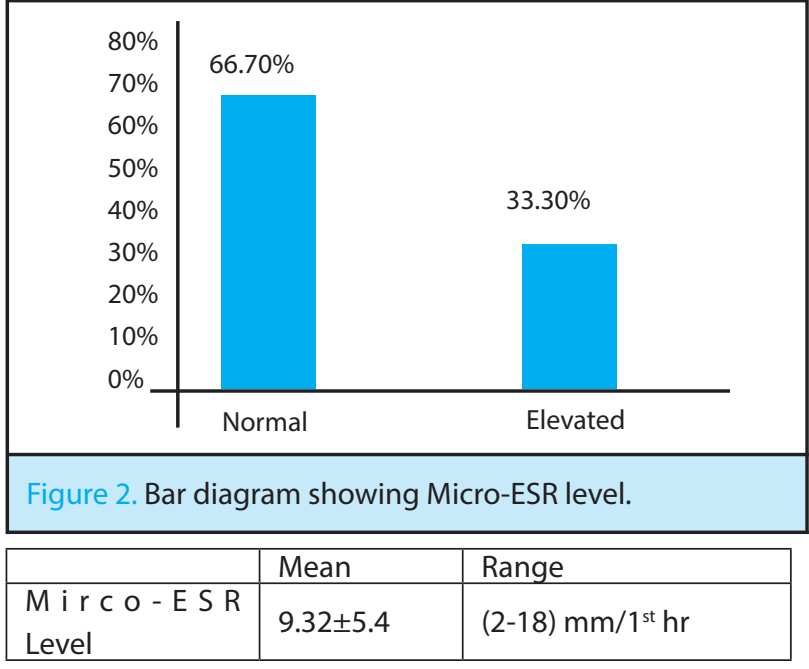

Among 50 babies with normal micro-ESR level, one (2\%) baby was diagnosed as confirm sepsis, 27 (54\%) as probable sepsis and 22 (44\%) babies as suspected sepsis. Whereas out of 25 babies with elevated micro- ESR level, 12 (48\%) babies were diagnosed as confirm sepsis and $13(52 \%)$ as probable sepsis. Similarly, among 50 babies with normal micro-ESR level, CRP was positive in 26 (52\%) babies and negative in 24 (48\%). Whereas out of 25 babies with elevated micro-ESR level, all 25 (100\%) babies had positive CRP (Table 3 ).

\begin{tabular}{|lll|}
\hline \multicolumn{3}{|l|}{ Table 3. Micro-ESR level in accordance with sepsis } \\
types and CRP. & \multicolumn{2}{|c|}{ Micro ESR Level } \\
\hline Variables & $\begin{array}{l}\text { Normal } \\
\leq 15 \mathrm{~mm} \text { in } 1^{\text {st }} \mathrm{hr}\end{array}$ & $\begin{array}{c}\text { Elevated } \\
\text { Sepm in } 1^{\text {st }} \mathrm{hr}\end{array}$ \\
$\begin{array}{l}\text { Sepsis Types } \\
\text { Confirm Sepsis }\end{array}$ & $\mathrm{n}(\%)$ & $\mathrm{n}(\%)$ \\
$\begin{array}{l}\text { Probable Sepsis } \\
\text { Suspected } \\
\text { Sepsis }\end{array}$ & $27(54)$ & $12(48)$ \\
$\begin{array}{l}\text { Total } \\
\text { C-Reactive } \\
\text { Protein (CRP) }\end{array}$ & $22(44)$ & $0(0)$ \\
Negative & $50(100)$ & $25(100)$ \\
Positive & $24(48)$ & $0(0)$ \\
Total & $26(52)$ & $25(100)$ \\
\hline
\end{tabular}

\section{DISCUSSION}

Neonatal Sepsis is the commonest cause of neonatal mortality and morbidity resulting in $30-50 \%$ of total neonatal deaths in developing countries. ${ }^{16,17}$ Considering its high mortality and morbidity, a specific diagnostic marker eg. Interleukin 6, Interleukin 8, Procalcitonin with high sensitivity and specificity is desirable in 
neonatal sepsis. However, these tests are not easily available in our country and also not cost-effective. ${ }^{18}$ Apart from other septic screening tests mentioned in Box 1, micro ESR is a single, cheap, easy to perform, less time consuming with sensitivity and specificity of $63.3 \%$ and $60 \%$ respectively. ${ }^{19}$

A study done by Kafle R et al. in Universal College of Medical Sciences, Bhairahawa, Nepal found $6 \%$ of babies with confirm sepsis and $12 \%$ had elevated micro -ESR level. ${ }^{18}$ Similarly, a study done by Ghaliyah AZ et al in Yenepoya Medical College Teaching Hospital, Mangalore, India found 32\% confirm sepsis with a $38 \%$ elevated micro-ESR level. ${ }^{4}$ In our study also 13 (17.3\%) babies had confirmed sepsis and a total of 25 (33.3\%) babies had raised micro-ESR level showing the significance of micro-ESR level concerning confirm sepsis.

Shah GS et al. at BPKIHS, Dharan, Nepal described the maternal history of PROM, maternal history of foulsmelling liquor, prematurity, low birth weight and low Apgar score at birth were the strong risk factors for early-onset neonatal sepsis. ${ }^{1}$ Similarly, in this study, also maternal PROM (44\%) and preterm (29.3\%) were the commonest risk factors highlighting its major role for sepsis in babies.

CRP is an inflammatory acute-phase reactant that promotes the healing of the injured tissue. ${ }^{20}$ CRP is also a good marker of sepsis with sensitivity and specificity of $77.8 \%$ and $66.7 \%$ respectively. ${ }^{21}$ In Ghaliyah AZ et al study, ${ }_{1}^{4}$ out of 19 babies with elevated micro-ESR level, 12 (63.2\%) has positive CRP whereas in our study all twenty-five (100\%) babies with elevated microESR had positive CRP showing the significance of CRP with the raised micro-ESR level in sepsis diagnosis.

\section{CONCLUSIONS}

Neonatal Sepsis is the commonest cause of neonatal mortality and morbidity. ${ }^{15}$ The bedside micro-ESR level test showed significance in the diagnosis of neonatal sepsis for better management in the NICU. Since this is a study of a single institution with convenient sampling, the outcome cannot be generalized.

\section{ACKNOWLEDGEMENTS}

Our sincere hearty thanks and acknowledgment to all the Pediatric, Pathology and Microbiology Department faculties, post-graduate residents and nursing staff for their tireless effort on better neonatal care during its diagnosis and management of neonatal sepsis to make this study successful. At last but not the least, our sincere gratitude and thanks to all the neonates and their parents, without them this research would not be possible.

Conflict of Interest: None.

\section{REFERENCES}

1. Shah GS, Budhathoki S, Das BK, Mandal RN. Risk factors in early neonatal sepsis. Kathmandu Univ Med J. 2006 AprJun;4(2):187-91. [uuMed | Full Text]

2. Population division, Ministry of Health and Population (MOHP), Government of Nepal. Infant and child mortality. In: New ERA and Macro International Inc. eds. Nepal Demographic and Health Survey (NDHS) 2016. Kathmandu: Ministry of Health and Population, New ERA, and Macro International Inc; 2016. 142p. [Full Text]

3. Manandhar SR, Ojha A, Manandhar DS, Shrestha B, Shrestha D, Saville N et al. Causes of stillbirths and neonatal deaths in Dhanusha district, Nepal: A verbal autopsy study. Kathmandu Univ Med J. 2010;8(29):62-72. [PubMed | Full $\underline{\text { Text }} \mid \underline{\text { DOI] }}$

4. Ghaliyah AZ, Prabhu AS, Sahana KS. Role of micro- ESR in the evaluation of suspected sepsis in neonates. International Journal of Sciences and Research. 2015 Aug;4(8):311-4. [ [Full Text]

5. Sankar MJ, Agrawal R, Deorari AK, Paul VK. Sepsis in the newborn. Indian J Pediatr. 2008 Mar;75(3):261-6. [PubMed |

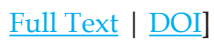

6. Ghai OP, Gupta P. Ghai Essential Pediatrics. 7th ed. New Delhi (India): CBS Publications; 2010. 136-7. [Full Text]

7. Buch AC, Srivastava V, Kumar H, Jadhav PS. Evaluation of hematological profile in early diagnosis of neonatal sepsis. Int J Basic App Med Sci. 2011 Sept-Dec;1(1):1-6. [Full Text]

8. Desai P, Shah AN, Pandya T, Desai P, Pandya T. C-Reactive Protein, immature to total neutrophil ratio and micro ESR in early diagnosis of neonatal sepsis. Int J Biomed Adv Res. 2014;5(8):364-6. [Full Text]

9. Manandhar SR. Outcome of surfactant replacement therapy in preterm babies with hyaline membrane disease at neonatal intensive care unit of a tertiary hospital. Birat Journal of Health Sciences. 2018; 3(3):486-8. [Full Text | DOI]

10. Manandhar SR, Manandhar DS. Use of antibiotics in newborns with maternal history of premature rupture of membrane. Journal of Kathmandu Medical College. 2016 Jan Mar;2(5)15:3-10. [Full Text | DOI]

11. Shenoi A, Nagesh NK, Maiya PP, Bhat SR, Rao SD. Multicenter randomized placebo controlled trial of therapy with intravenous immunoglobulin in decreasing mortality due to neonatal sepsis. Indian Pediatr. 1999;36:1113-8. [PubMed | Full Text] 
12. Gerdes JS. Clinicopathological approach to the diagnosis of neonatal sepsis. Clin Perinatol.1991;18(2):361-81. [PubMed | $\underline{\text { Full Text }}$ | DOI]

13. Diwakar KK, Rosul G. Revised look at micro erythrocyte sedimentation rate in neonates. Indian Pediatr. 1999;36(7):703-5. [PubMed | Full Text]

14. Ballard JL, Khoury JC, Wedig K, Wang L, Eilers-Walsman BL, Lipp R. New Ballard score, expanded to include extremely premature infants. J Pediatr. 1991 Sep;119(3):41723. [ubMed | Full Text $\mid \underline{\text { DOI] }}$

15. Gomez B, Mintegi S, Benito J, Egirum A, Garcia D, Astobiza E. Blood culture and bacteremia predictors in infants less than three months of age with fever without source. Pediatr Infect Dis J. 2010;29(1):43-7. [PubMed | Full Text | DOI]

16. Bang AT, Bang RA, Bactule SB, Reddy HM, Deshmukh MD. Effect of home based neonatal care and management of sepsis on neonatal mortality: field trial in rural India. The Lancet. 1999 Dec;354(9194):1955-61. [ㅁuMed | Full Text | DOI]
17. Stoll BJ. The global impact of neonatal infection. Clin Perinatol. 1997 Mar;24(1):1-21. [PubMed | Full Text | DOI]

18. Kafle R, Yadav J, Gupta BK, Gupta BK. Role of micro ESR in the evaluation of neonatal sepsis. Journal of Universal College of Medical Sciences. 2019;7(2):25-9. [Full Text | DOI]

19. Walliullah SM, Islam MN, Siddika M, Hossain MA, Chowdhury AK. Role of micro-ESR and I/T ratio in the early diagnosis of neonatal sepsis. Mymensingh Med J. 2009 Jan;18(1):56-61. [ㅁubMed]

20. Jaye DL, Waites KB. Clinical applications of C-reactive protein in pediatrics. Pediatr Infect Dis J. 1997 Aug;16(8):73546. [PubMed | Full Text | DOI]

21. Lakhey A, Shakya H. Role of sepsis screening in early diagnosis of neonatal sepsis. Journal of Pahology of Nepal. 2017;7(1):11103-10. [Full Text | DOI]

This work is licensed under a Creative Commons Attribution 4.0 International License. The images or other third party material in this article are included in the article's Creative Commons license, unless indicated otherwise in the credit line; if the material is not included under the Creative Commons license, users will need to obtain permission from the license holder to reproduce the material. To view a copy of this license, visit http://creativecommons.org/licenses/by/4.0/ 